\title{
Community Language Learning (CLL) in Tertiary Level: A Learner Friendly Approach to ELT in Bangladesh
}

\author{
Tazreen Jahan Bari \\ Bangladesh University of Professional, Dhaka. Bangladesh \\ 18151004@student.bup.edu.bd
}

\section{ARTICLE HISTORY}

\author{
Received : 2020-10-09 \\ Revised : 2020-11-16 \\ Accepted :2020-12-01
}

\section{KEYWORDS}

Community Language Learning ELT

Language learning

Tertiary level

\begin{abstract}
This paper entitled "CLL in Tertiary Level: A Learner Friendly Approach to ELT in Bangladesh" aims to analyse the problems faced by tertiary level language learners in Bangladesh. This paper shows how Community Language Learning (CLL) can be a learner-friendly approach that creates an environment and process fit for maximum efficiency in target language learning. This paper analyses the quantitative data collected via questionnaire from fifty tertiary level students of Bangladesh from five universities across Bangladesh. This study reveals that tertiary level students face more barriers in classroom participation due to selfconsciousness and anxiety. This study further reveals that using the CLL method that treats learners like a whole person allows them to take responsibility for their learning process. It also promotes small study groups consisting of peers and a counsellor-teacher to provide a more efficient learning environment is friendly to the learners. Thus, this study asserts that CLL is the most learner-friendly and efficient approach to ELT in the tertiary level and opens future research possibilities on how this method can be implemented.
\end{abstract}

\section{Introduction}

English Language Learning is something most students face throughout their academic lives in Bangladesh. However, upon entering the tertiary level, students face difficulty learning that is different from being just technical as they face anxiety and shyness induced by a new sense of adulthood. In this context, students of the tertiary level find it more comfortable with making mistakes in a learning environment where they are seen as whole persons and given a chance to learn from their peers and control their learning process.

Charles A. Curran in his book, "Counselinglearning: a whole-person model for education" (1972) has developed a language teaching model based on a relationship between teacher and learner that resembles that of a client and counsellor (Curran,1972, p. 113). Curran explains that the teacher/counsellor by "Understanding the language of feeling, answers in the language of cognition" (as cited in Richards, Dudeney \& Rodgers, 2001, p. 95). This learning model based on the counsellor-teacher method is the community language learning method or CLL, emphasising the importance of trusting relationships and comfortable learning space in the language learning process. CLL method promotes small scale classrooms where the students or learners can learn from each other and feel comfortable enough to overcome learning anxieties.

Although a CLL is a reasonably well-researched concept, there is a significant lack of research in this field from the students' perspective. Especially in Bangladesh, this study attempts to focus on the tertiary level students of Bangladesh and create a platform for their voices to be heard. This study entitled " $C L L$ in Tertiary Level: A Learner Friendly Approach to ELT in Bangladesh" suggests that Community Language Learning (CLL) considers the learner's psychological needs by creating a learning process. It based on mutual trust among peers can offer a learner-friendly environment, thus ensuring a more efficient learning process.

This paper's general objective is to show how CLL is the most learner-friendly and efficient ELT method for tertiary level students. To this purpose, this study aims to fulfil the following specific objectives: (1) To determine the problems faced by tertiary level students in English language learning and (2) To show the efficiency of CLL method in resolving these problems and becoming the most student-friendly method for ELT. In order to examine how CLL can be the most learner-friendly approach to ELT at the tertiary level, this paper asks the following research questions:

What are the problems faced by tertiary level students in Language Learning classroom? This question will enable the researcher to understand the students' most frequent language learning problems and identify the most common learning barriers. The questionnaire is designed to identify problems specific to learners' comfort and learning anxiety in a classroom environment. 
How can Community Language Learning resolve these problems? This question resonates with more specific questions in the questionnaire that will give the researcher ideas about how using CLL method can lessen some of the problems that the tertiary level students face. The questionnaire will ask questions that will compare the two approaches: traditional and CLL and choose the one that fits their learning style best.

\section{Literature Review}

Anxiety regarding language learning has been a topic for discussion for a long time. Many researchers have given their opinion regarding this issue. Anxiety can significantly hamper the learning process. As Scovel (1978) has suggested, learner anxiety can be multiple fallbacks, whereas facilitating learner anxiety can produce positive results in the learning process. Although it is common for learners to feel anxiety, adult learners especially experience anxiety and frustration induced by a sense of ambiguity in their dual state as an adult and a child-like learner (Rardin et al. 1988). Zou (1998) in "Rethinking Empowerment: The Acquisition of Cultural, Linguistic, and Academic Knowledge" explains that, for effective teaching and meaningful learning, the most crucial factor is establishing trusting relationships. (Zou, 1998, p.5). However, most learning strategies do not focus on community building through trusting relationships. CLL can offer such relationships.

Paoling Liao (2014) has taken a modern take on CLL in his study, "Flipped Learning: Integrating Community Language Learning with Facebook via Computer and Mobile Technologies to Enhance Learner Language Performances in Taiwan." It has shown how online communities can also serve as communities for language learning where learner anxiety is alleviated through the feeling of community (Liao, 2014, p. 92). Online communities are growing day by day, and they can serve as a safe space for language learners who depend on a comfortable learning environment for better language learning. La Forge (1979) wrote in "Reflection in the Context of Community Language Learning," about using CLL for speaking English at junior college in Japan. He found that "the quality of the English showed a remarkable improvement." (La Forge, 1979, p. 252), which shows how CLL can be a viable English qualityarners facing anxiety in the classroom. Koba, Ogawa and Wilkinson in "Using the Community Language Learning Approach to Cope with Language Anxiety" (2000) asserts that, "a sense of security is woven into each activity of a typical CLL cycle along with comfort" (Community Language Learning section, para. 6). This sense of security can go a long way in case of language learners dealing with language anxiety. Gallagher's (1973) study on a comparative study between CLL and other traditional methods reveals that students in a CLL group have more positive changes than students in a traditional group. In her study, Fatemeh Zarrabi also explores the positive effect of interdependent learning (Zarrabi, 2014, p.126). Samimy and Rardin in "Adult Language Learners' Affective Reactions to Community Language Learning: A Descriptive Study" (1994) examine "whether or not CLL is facilitative in alleviating emotional barriers that hinder language acquisition." This study found that "a majority of them experienced a reduction of anxiety" (Samimy \& Rardin, 1994, p.387). Although much research has been done on CLL, there is a significant lack of work examining this method from the tertiary level learner's perspective, creating a research gap. This research examines this niche of language learning to eradicate some of the said gaps by providing a nuanced understanding of learning anxiety and learners' comfort in the classroom. Bringing in the learner's perspective will emphasise the learners' specific needs and how that can be fulfilled by using the CLL approach.

\section{Method}

This research has been done using a quantitative method using data collected from primary sources. The sources consist of a tertiary level student studying in Bangladesh. The researcher has made a questionnaire that asks questions regarding classroom participation, comfortable learning methods, and learner anxiety while learning English as a foreign language.

By using this questionnaire, the data has been collected via E-mail, WhatsApp and Facebook from fifty students studying in five different universities across Bangladesh namely Bangladesh University of Professionals, University of Dhaka, Rajshahi University, North South University and BRAC University. Bangladesh University of Professionals, University of Dhaka and Rajshahi University are three prominent public universities of Bangladesh and therefore follow similar learning structures and environment. North-South University and BRAC University are two leading private universities of Bangladesh that again follow similar learning environment. All five universities have students coming from various backgrounds and varying degrees of exposure to the target language. Therefore, the tertiary students who have participated come to cover both public and private university learning environments, making the research more far-reaching. The response collected from students has been converted to numerical data. This data has then been placed on graphs and charts to expose the patterns in a learning process that the researcher has then analysed.

\subsection{Conceptual Framework}

This research has been organised into two main sections, and the questionnaire reflects that, as shown in Figure 3.1. The questionnaire is used to collect data from fifty tertiary level students studying in five universities of Bangladesh. 


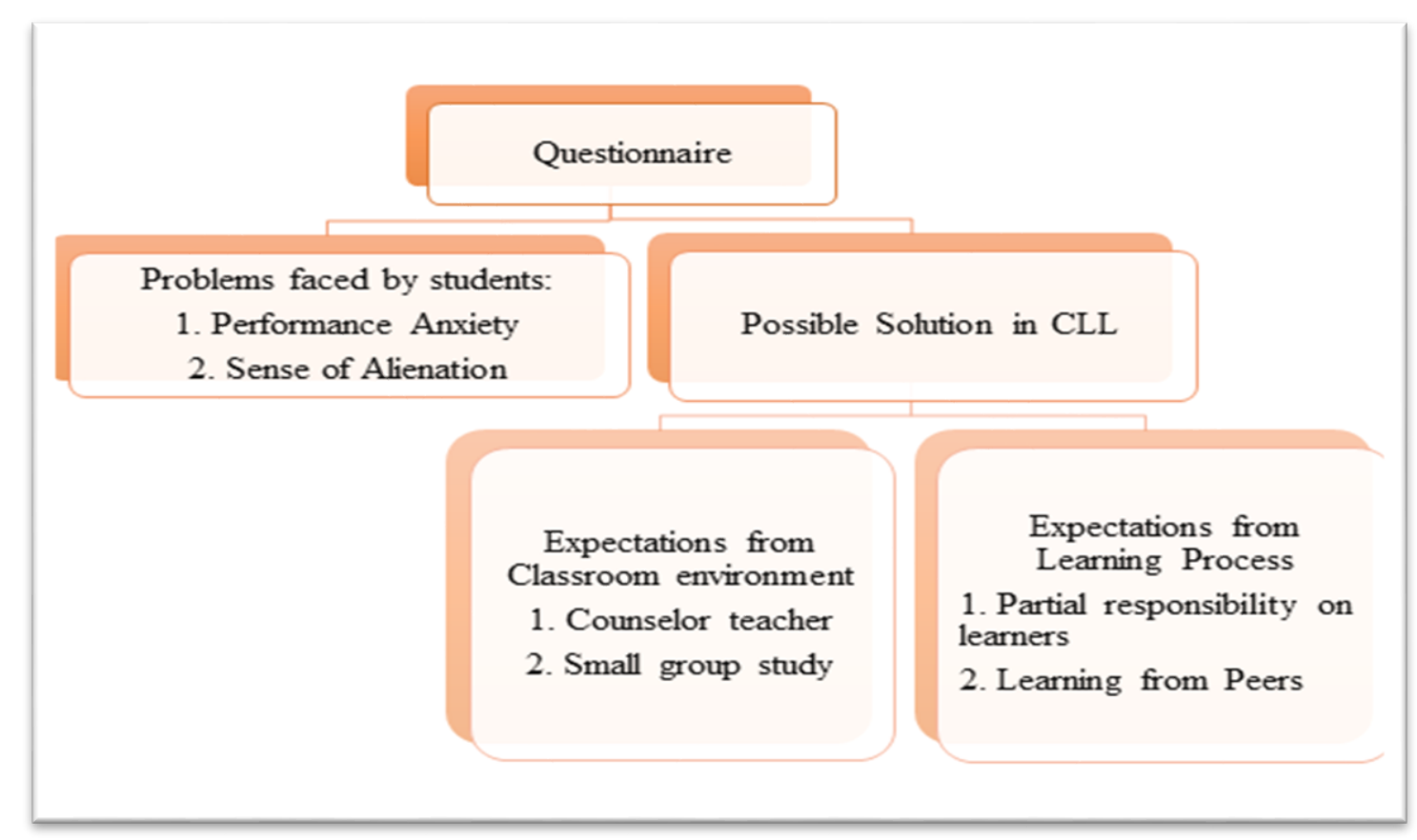

Figure 3.1 Conceptual Framework

The first part of the questionnaire is used to identify what kind of problems tertiary level students in Bangladesh face regarding ELT. As Bengali is the mother tongue of majority students in Bangladesh, most students, especially in the tertiary level, face anxiety issues, lack of self-confidence. As students at this stage start to see themselves as individual adults, it clashes with the learner identity perceiving them young and prone to mistakes. Which is why this section of the questionnaire is designed to find out specific problems that students face in EFL classrooms

The second portion of the questionnaire tries to see how different aspects of CLL can help alleviate the problems generally faced by tertiary level students. It does so by providing questions to the students that differentiate between a traditional learning technique and a CLL method's learning strategy. The researcher suggests CLL as a solution to classroom anxiety and learning barriers. Thus, CLL can be suggested as a learner-friendly approach that solves most frequently faced problems by tertiary level students.

\section{Findings}

Whether students feel shy while answering questions in the target language has revealed that $68 \%$ feel shy, whereas only $32 \%$ feel comfortable classroom participation. $72 \%$ of students have said that they only participate in classroom activities when forced to do so (see Appendix B).
Barriers Faced by Learners in Language Learning Classroom

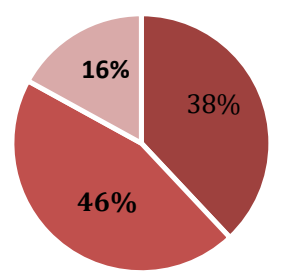

- Self-consciousness

- Nervousness

- Unfriendly Environment

Figure 4.1 Barriers faced by students in language learning class

The collected data further revealed that $38 \%$ (19 out of 50 students) of learners find themselves suffering from self-consciousness, $46 \%$ ( 23 out of 50 students) learners are inactive due to nervousness and nearly $16 \%$ ( 8 out of 50 students) of the total student body find the classroom and instructor or learning environment unfriendly. This data has been illustrated in Figure 4.2.

Whether as adults, they have grown weary of making mistakes, $56 \%$ (28 out of 50 students) answered that this sense of adulthood makes them think they cannot make mistakes. When asked to specify an unfriendly environment, $68 \%$ agreed that the traditional role induces it. $32 \%$ of student agreed that a large-scale classroom made active participation more stressful. 
The data reveals that only $22 \%$ of the students preferred traditional classrooms (which are generally large scale in the context of Bangladesh) over small study groups or communities of friends based on mutual trust preferred by $78 \%$ of the students. This data has been illustrated in Figure 4.2.

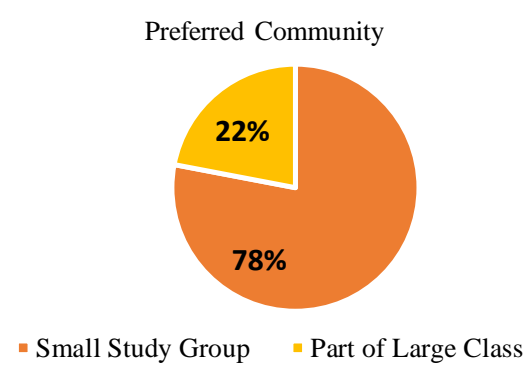

Figure 4.2 CLL in relation to preferred classroom

Furthermore, upon being questioned about whether students will feel more comfortable speaking and participating in the class activities if the teacher was someone like a counsellor/mentor, $88 \%$ (44 out of 50 students) of the total student body answered in the affirmative. In comparison, only $12 \%$, which consists of only six students out of 50, preferred a traditional instructor. This result can be seen in the pie-chart below:

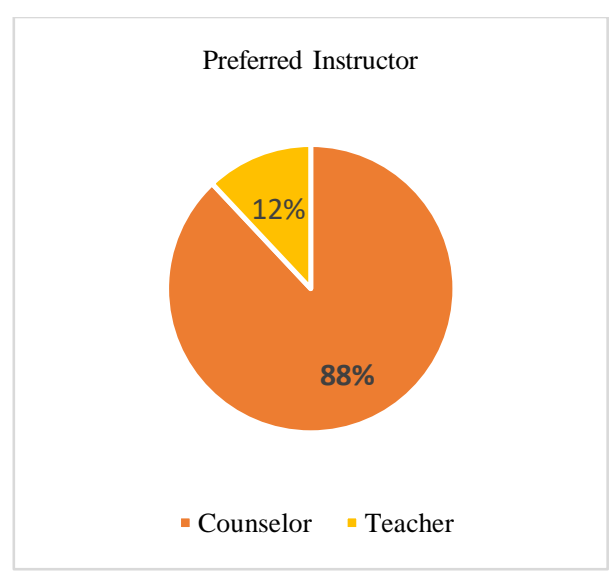

Figure 4.3 Preferred instructor in class

In answer to whether they learn better when discussing things with peers or in the classroom, $78 \%$ of the latter spoke. Moreover, $84 \%$ of students have said that they tend to seek out their fellow peers before the instructor when they face any problem regarding learning materials (See Appendix B). When the students are asked if they can take responsibility for their learning process, only $6 \%$ of students said no whereas $34 \%$ of students said yes, and $60 \%$ of students said, "to some extent". This result can be seen illustrated in Figure 4.4.
Autonomy Over learning Process

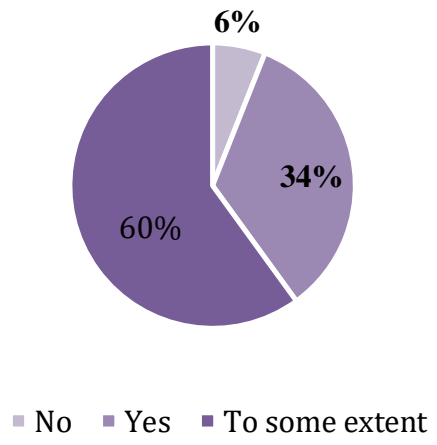

Figure 4.4 CLL in relation to preferred learning process

Furthermore, upon being asked how they learn well, 66\% (33 out of 50) students answered they prefer self-study based learning over instructed learning process which is preferred by remaining 34\% (17 out of 50) students (See Appendix B).

\section{Discussion}

\subsection{Problems Faced by Tertiary Level Students}

As the data shows, most learners feel classroom anxiety as adult learners. This anxiety is expressed through the lack of classroom participation in tertiary level students based on their shyness. Which asks to examine this barrier further to see what problems are specific to the tertiary level students.

Adult learners such as tertiary level students more often than not suffer from self-consciousness and nervousness due to their newly developed sense of identity as a whole-person or new-adult. As adults, most people feel that they are not allowed to make mistakes. It is why among tertiary level students who are new adults, yet students prone to mistakes in a language learning classroom, self-consciousness becomes a barrier to their language learning process.

Another barrier to their language learning process is their instructor. A traditional instructor will treat them like students rather than a colleague or friend. Although this superior-inferior relationship works with younger students, tertiary level students are more comfortable with an instructor who can see eye to eye, creating an equal ground of respect between the learner and instructor. As the data shows, most students prefer a mentor or counsellor as an instructor rather than an instructor in the traditional sense. Moreover, a traditional instructor is not bound to consider the student's psychological needs as a counsellor would.

\subsection{CLL and Expectations from Classroom}

Tertiary level students are easily subjected to a sense of alienation in a large-scale classroom as it can create an "Intimidating atmosphere" (Nuraini, 2016, 
p.12). The data shows that most students prefer a smallscale classroom as they are quickly left behind and intimidated by a large classroom which is the reality for most Bangladeshi language learners in the tertiary level. The student body in classrooms can be anywhere between 50-150, which is undoubtedly anxietyinducing, especially in adult learners who are anxious about the idea of making mistakes in front of a large crowd. A study shows that providing a small-scale peer group for classroom activities revealed that "students were impressed and happy" with their work "because of the supportive environment provided through working with peers in a group" (Mahmoud, 2014, p.261). The collected data draws a similar conclusion from the students as upon being asked, most students replied that they feel more comfortable in a small-scale classroom. CLL makes CLL a better option than other language learning methods, as CLL specifically focuses on giving the learners a small-scale classroom to lessen classroom anxiety through community feeling.

A classroom designed to fit the CLL mentor of language learning will also have an instructor who takes on a counsellor or mentor's role rather than the traditional role of an instructor. As the data reveals, most students of tertiary level prefer this type of instructor over traditional ones. As learners prefer instructors who are friendly and see them on equal ground, it will provide a more comfortable environment for them, which will enable them to learn better than in a traditional classroom. They will feel more comfortable to look past the initial shyness and participate in classroom activities. Furthermore, they will feel comfortable to reach out to the instructor when in need which will enable them to learn from their mistakes without being discouraged.

\subsection{CLL and Expectations from the Learning Process}

To understand how tertiary level students, learn best, the researcher has first examined their preference in learning. As the data shows, most learners prefer to ask for guidance to their fellow peers rather than asking their instructor when faced with a learning barrier or problem. It can become a learning barrier as the other learners may not always know the right answer or be inadequate to give them a proper solution to their problem. Furthermore, this creates a gap between the instructor and students, becoming an obstacle in the learner's progression path. Which again points to CLL as a solution as CLL offers the students an instructor who is more open to the learners; therefore, more approachable than the traditional instructor.

Furthermore, this suggests that they prefer to have autonomy over their learning process. This idea is reinforced when the students are asked if they find themselves capable of taking responsibility for their learning process. Most students replied that some students replied in the affirmative, and only a few students replied negatively. It shows that almost all students like to have autonomy over their learning process, and most of them think they can take partial responsibility for their learning process. A study done on Saudi University Students reveals that letting the students be in charge of their assigned tasks made feel "that they became more responsible for their work as creators of ideas and builders of meaning and knowledge" (Mahmoud, 2014, p.262). It makes CLL the most suitable method for tertiary level students as it allows the learner to have autonomy over their learning process.

However, as most students answered, "to some extent", it reflects that although they want autonomy over their learning process, some degree of guidance and control is needed, which is not surprising as most tertiary level students are at the threshold of adulthood not completely adult yet. Meaning they find themselves wanting to be autonomous yet are prone to mistakes when given full responsibility. Which is why CLL can again be the perfect solution for these students. A study done on intermediate-level Iranian EFL students shows that a shift from "teacher dependence to learner interdependence" can positively change EFL students' learning progress (Zarrabi, 2016, p. 126). CLL allows the learners to have a degree of autonomy over their learning process yet bounds them by the sense of community or interdependence, allowing them to take guidance and help when in need.

\section{Conclusion}

"There is a huge discrepancy between what the students expect and what the real scenario is in Bangladesh" in the context of language learning in tertiary level (Haque, 2014, p.63). Therefore, it is of great significance to understand the learning barriers these students face and mitigate them as far as possible. The research has attempted to examine the problems tertiary level students face in language learning and how these problems can be resolved using Community Language Learning or CLL. The data analysis has revealed that most students face self-consciousness and alienation due to their sense of identity as a new adult and unfriendly instructors and large classrooms. The data further shows that most students would prefer a counsellor and small group, which will offer them a more comfortable learning environment by relieving psychological anxiety induced by learning in an alienating environment. Furthermore, tertiary level students are capable of taking responsibility for both their learning process and prefer learning from peers or on their own.

Community Language Learning can offer a counsellor, small study groups and autonomy over the learning process to the learners. As tertiary level students are usually new adults trying to cope with their new responsible and autonomous selves, CLL fits their needs perfectly. Thus, CLL appears to be the most student-friendly approach to ELT for tertiary level 
students. Although most researchers focus on the efficiency and practicality of language learning methods, it is crucial to give the learners a platform to voice their needs and preferences. It is especially true for tertiary level students who have had time to understand their learning needs.

This research has attempted to be a reliable platform for representing the learners' voice and bringing forth their opinions in the context of language learning barriers and classroom anxiety. From analysing the results and providing a nuanced understanding of the problems at hand, this study recommends partial or full implementation of the CLL in tertiary level classrooms of Bangladesh to mitigate the learning barriers in this context and encourage a more efficient learning process. Future researchers can elaborate on this novel way of looking at language learning barriers to find new ways of developing a learner-friendly classroom.

\section{References}

Curran, C. A. (1972). Counseling-learning: A Wholeperson Model for Education. New York: Grune and Stratton.

Gallagher, R. M. (1973). An Evaluation of a Counselling-Community Learning Approach to Foreign Language Teaching or CounsellingLearning Theory Applied to Foreign Language Learning. Loyola ECommons: Dissertations. Retrieved

from https://ecommons.luc.edu/cgi/viewcontent.cgi? $\underline{\text { article }=2444 \& \text { context=luc_diss }}$

Haque, S. (2014). Expectation of Tertiary Students of Bangladesh from ELT Classrooms. Journal of NELTA, 19(1-2), 56-64.

Koba, N., Ogawa, N., \& Wilkinson, D. (2000). Using the Community Language Learning Approach to Cope with Language Anxiety. The Internet TESL Journal, 6(11). Retrieved from http://iteslj.org/Articles/Koba-CLL.html

La Forge, P. G. (1979). Reflection in the Context of Community Language Learning. English Language Teaching Journal, 33(4), 247-254. Retrieved from https://eric.ed.gov/?id=EJ206586

Liao, P. (2014). Flipped Learning: Integrating Community Language Learning with Facebook via Computer and Mobile Technologies to Enhance Learner Language Performances in Taiwan. Multidisciplinary Social Networks Research, 437, 92-101. DOI: 10.1007/978-3662-45071-0_8
Mahmoud, M. M. (2014). The Effectiveness of Using the Cooperative Language Learning Approach to Enhance EFL Writing Skills among Saudi University Students. Journal of Language Teaching and Research, 5(3), 616-625. DOI:10.4304/jltr.5.3.616-625

Nuraini, K. (2016). The Barriers of Teaching Speaking English for EFL Learners. ELLITE Journal of English Language, Literature, and Teaching, 1(1), 7-14.

Rardin, J. P., Tranel, D. D., Tirone, P. L., \& Green, B. D. (1988). Education in a New Dimension: The Counseling-Learning Approach to Community Language Learning (1st ed.). CounselingLearning Publications.

Richards, J. C., Dudeney, G., \& Rodgers, T. S. (2001). Approaches and Methods in Language Teaching. Cambridge University Press.

Samimy, K. K., \& Rardin, J. P. (1994). Adult Language Learners' Affective Reactions to Community Ianguage Learning: A Descriptive Study. Foreign Language Annals, 27(3), 379-390. DOI: 10.1111/j.1944-9720.1994.tb01215.x

Scovel, T. (1978). The Effect of Affect on Foreign Language Learning: A Review of the Anxiety Research. Language Learning, 28(1), 121-142. DOI: $10.1111 / \mathrm{j} .1467-1770.1978 . t b 00309 . \mathrm{x}$

Zarrabi, F. (2016). A Study on Cooperative Language Learning : The Impact of CLL Approach on English Language Proficiency on EFL Learners. European Journal of Education Studies, 1(2), 119-132.

Zou, Y. (1998). Rethinking Empowerment: The Acquisition of Cultural, Linguistic, and Academic Knowledge. TESOL Journal, 7(4), 56 